\title{
Cidade educadora e o programa linhas do conhecimento: representações sociais de professoras ${ }^{1}$ de educação infantil
}

\author{
Educating city and the lines of knowledge program: social \\ representations of early childhood teachers
}

Sueli Pereira Donato ${ }^{1}$
Romilda Teodora Ens ${ }^{2}$

Rosane de Jesus ${ }^{3}$

\section{Resumo}

O artigo analisa as representações sociais (RS) de professoras que atuam nos Centros Municipais de Educação Infantil (CMEIs), com a etapa da pré-escola e na interface com o "Programa Linhas do Conhecimento", de Curitiba/PR sobre "cidade educadora". Com opção pela abordagem qualitativa, tomamos o aporte da Teoria das Representações Sociais e Teoria do Núcleo Central, para analisar as representações sociais com os dados produzidos a partir da aplicação da técnica de associação livre de palavras a 37 professoras. Após a

1 O uso da expressão professoras representa as participantes da pesquisa, as quais assim se autodenominaram, ou seja, informaram por ocasião da pesquisa como sendo do gênero feminino.

${ }^{1}$ Doutora em Educação pela Pontificia Universidade Católica do Paraná - PUCPR.

Professora do Programa de Pós-Graduação Stricto Sensu em Educação e Novas Tecnologias do Centro Universitário Internacional Uninter. Pesquisadora da FAMPECT. Pesquisadora da FAMPECT. Atua e desenvolve pesquisas na área da Educação com ênfase na formação de professores, relações entre escola-universidade-cidade educadora, tecnologias e representações sociais.

2 Doutora em Educação pela Pontifícia Universidade Católica de São Paulo - PUC-SP. Pós Doutora pela Universidade do Porto/Portugal. Pesquisadora Produtividade pela Fundação Araucária - Paraná. Professora Titular do Programa de Pós-Graduação em Educação, Mestrado e Doutorado, na linha História e Politicas da Educação, da Pontificia Universidade Católica do Paraná (PUCPR).

${ }^{3}$ Mestranda em Educação e Novas Tecnologias no Centro Universitário Internacional Uninter. Graduada em Pedagogia pela Pontificia Universidade Católica do Paraná. Pósgraduação em Educação Infantil e Alfabetização, Educação Especial e Psicopedagogia. Atua como pedagoga na educação infantil e educação especial em instituições públicas municipais de Curitiba/Pr.

Interfaces da Educ., Paranaíba, v.11, n.32, p. 384 - 411, 2020 
preparação do corpus, este foi processado no software EVOC para a análise prototípica, confirmada pela Análise de Similitude processada pelo software Iramuteq, a qual gerou a árvore máxima. As representações sociais das professoras participantes da pesquisa sobre cidade educadora mostram essa cidade como espaço/tempo que, ao envolver a ampliação cultural, cria uma comunidade educadora que contribui para assegurar à criança os direitos de cidadania e que requer a valorização do(a) professor/professora.

Palavras-chave: Representação Social. Educação Infantil. Cidade Educadora. Programa Linhas do Conhecimento

\section{Abstract}

The article analyzes the social representations (SR) of teachers who work in the Municipal Centers for Early Childhood Education - CMEIs, with the preschool stage and in the interface with the "Lines of Knowledge Program", in Curitiba / PR about "educating city". With an option for the qualitative approach, we take the contribution of the Social Representations Theory and the Central Nucleus Theory, to analyze the social representations with the data produced from the application of the free association of words technique to 37 teachers. After the preparation of the corpus, it was processed in the EVOC software for the prototypical analysis, confirmed by the Similitude Analysis processed by the Iramuteq software, which generated the maximum tree. The social representations of the teachers participating in the research about an educating city show this city as a space / time that, by involving cultural expansion, creates an educating community that contributes to ensure children's rights of citizenship and that requires the teacher's appreciation.

Keywords: Social Representation. Child Education. Educating City. Lines of Knowledge Program 


\section{Introdução}

Ao tomarmos o conceito de Cidade Educadora como aquele que "[...] está directamente relacionado com outros, tais como, a equidade, a cidadania inclusiva, a coesão, a sustentabilidade ou a educação para a paz" (BELLOT, 2013, p. 20), temos como pressuposto de que no seu espaço poderá ser vivenciado/concretizado o direito fundamental da pessoa à educação. Nessa perspectiva, os(as) professores/professoras, em espaços formais e não formais de educação no contexto de sua cidade, especialmente quando essa em suas políticas públicas assume uma probabilidade educadora, são chamados(as) a orientar e contribuir com a formação conceitual e ética de seus habitantes, para os imbuir de uma dimensão qualitativa e comunitária que não menospreza a cooperação e a convivência ativa e solidária entre as pessoas de modo intergeracional, mas contribuem com a sociedade civil para efetivar o conceito de Cidade Educadora (POZO, 2013).

Mergulhados(as) na contemporaneidade, é nitida a amplitude de espaços educativos não formais presentes na cidade que contribuem, mesmo que informalmente, para o processo educacional, como museus, teatros, hortas comunitárias, praças, ruas, parques, bibliotecas, igrejas, meios de comunicação, mercado municipal, panificadora do bairro, concertos, entre outras possibilidades, pois os consideramos como espaços que suscitam um debate sobre o desemparedamento da escola por meio de práticas pedagógicas vinculadas à cultura, à própria vida num movimento em que ocorre da escola à cidade, e vice-versa, e não se reduza apenas para a vida e/ou descontextualizada da realidade. Além de privilegiarmos e reconhecermos a cidade como território pedagógico, concordamos com Moll (2013, p. 221-222) de que

[...] os conceitos de cidade educadora ou de cidade como pedagogia podem alargar nossa compreensão de educação, permitindo-nos transpor o currículo escolar clássico para além dos temas transversais, por meio da interlocução com o território urbano - em sua multiplicidade de espaços, convertendo-os em valiosas possibilidades pedagógicas na tessitura da aprendizagem. 
Essas possibilidades também contribuem para ressignificar a escola em seu tempo histórico, há muito identificada como espaço monolítico da educação e formação cidadã, podendo pensar, enfim, em uma reconversão da educação como espaço cultural e intelectual de ação política, de crítica, de reconhecimento do sujeito de direitos, que tem acesso ao saber sistematizado pelos homens, por exemplo na escola, mas não a ela confinado. Esse aspecto nos tem conduzido a refletir e "[...] pensar a cidade democrática e educadora, [... como] espaço de muitas trilhas [... ou seja], uma utopia a ser reanimada" (MOLL, 2013, p. 223), quando buscamos suscitar/reanimar reflexões sobre o modus operandis da escola - mais especificamente no contexto da educação infantil - primeira etapa da educação básica. Isso tudo nos possibilita pensar que fazer educação em interlocução com/na cidade em defesa de uma formação para/pela cidadania emancipatória é contribuir para minimizar a permanência do monopólio de uma escola pautada em uma lógica disciplinar e disciplinadora, geralmente fechada em seus muros e que se assemelha ao modelo panóptico descrito por Foucault (2007).

Esse tipo de escola restringe e/ou minimiza as possibilidades de cada professor/professora da educação infantil, conforme define a BNCC (BRASIL, $2017 b$, p. 43) em "[...] promover experiências nas quais as crianças possam fazer observações, manipular objetos, investigar e explorar seu entorno, levantar hipóteses e consultar fontes de informação para buscar respostas às suas curiosidades e indagações". Com base em Moll (2013), depreendemos que tal reconversão da educação implica em mudanças voltadas ao campo metodológico, como também paradigmáticas, por trazer para o debate, simultaneamente, os movimentos de reinvenção da escola e da "[...] cidade e, nela, a comunidade como lugares de convivência, de diálogo, de aprendizagens permanentes, na perspectiva do aprofundamento da democracia e da afirmação das liberdades" (p. 221-222).

Os dados produzidos para esse estudo fazem parte de uma pesquisa em andamento no âmbito de um programa stricto sensu em educação sobre "cidade educadora", com as representações sociais (RS) de 37 professoras 
que atuam na Rede Municipal de Ensino de Curitiba/PR, na etapa da Educação Infantil, e que tiveram alguma interlocução com o programa "Linhas do Conhecimento2" em suas práticas pedagógicas nos últimos três anos. A partir da compreensão de que "[...] as representações sociais não se constituem em abordagem metodológica, elas se referem a um fenômeno social e a uma teoria científica que se propõe a explicá-lo" (CAMARGO; WACHELKE; AGUIAR, 2007, p. 191), bem como a "[...] uma forma de expressão criativa dos sujeitos, situada numa interface do psicológico e do social" (ARRUDA, 2014, p. 121). Portanto, ao darmos voz às professoras dessa etapa de ensino a partir de uma pesquisa de abordagem qualitativa, com o aporte teórico da Teoria das Representações Sociais - TRS (MOSCOVICI, 1978, 2003) em sua vertente complementar, a Teoria do Núcleo Central (ABRIC, 2000), analisamos as representações sociais de professoras da educação infantil sobre o objeto representado: cidade educadora.

A estruturação do texto contempla, além dessa introdução, um estudo teórico e documental intitulado Cidade Educadora como potencial pedagógico: desemparedamento da infância. Na sequência, abordamos a TRS e sua importância para o estudo dos fenômenos educacionais, para adentrarmos na análise dos dados produzidos. Por fim, tecemos as considerações finais dessa etapa da pesquisa.

\section{Cidade Educadora como potencial pedagógico: o desemparedamento da infância}

A educação infantil como primeira etapa da educação básica é um direito da criança, assegurado pela Constituição Federal de 1988, normatizada pela Lei de Diretrizes de Bases da Educação Nacional (LDB), Lei $\mathrm{n}^{\circ}$ 9.394/1996, e orientada por documentos fundantes, entre eles os Parâmetros Nacionais de Qualidade para a Educação Infantil (2006), as Diretrizes Curriculares Nacionais para a Educação Infantil (DCNEI),

\footnotetext{
${ }^{2}$ Trata-se de uma política pública do governo municipal da cidade de Curitiba/PR, criada em 2017, cujo objetivo é oferecer oportunidades de acesso às crianças, aos estudantes e aos professores aos diferentes espaços da cidade (CURITIBA, 2018).

Interfaces da Educ., Paranaíba, v.11, n.32, p. 384 - 411, 2020
} 
revisadas em 2009, e a Base Nacional Comum Curricular (BNCC), implantada pela Resolução CNE/CP n 2/2017 (BRASIL, 1996, 2006, 2009, 2017a). Todos esses documentos convergem para a "[...] perspectiva que define a criança como ser competente para interagir e produzir cultura no meio em que se encontra" (BRASIL, 2006, p. 13).

Constatamos que o art. $9^{\circ}$, inciso I, das DCNEI/2009, ao tratar sobre práticas pedagógicas, definiu que as propostas para a educação infantil fossem planejadas de forma a promoverem "[...] o conhecimento de si e do mundo por meio da ampliação de experiências sensoriais, expressivas, corporais que possibilitem movimentação ampla, expressão da individualidade e respeito pelos ritmos e desejos das crianças" (BRASIL, 2009b). Esse aspecto é estabelecido pela Base Nacional Comum Curricular BNCC (BRASIL, 2017b), a partir dos eixos estruturantes das propostas pedagógicas e competências gerais da educação básica que, seus direitos de aprendizagem e desenvolvimento, asseguram condições para que as crianças de zero a cinco anos de idade "[...] aprendam em situações nas quais possam desempenhar um papel ativo em ambientes que as convidem a vivenciar desafios e sentirem-se provocadas a resolvê-los nas quais possam construir significados sobre si, os outros e o mundo social e natural" (p. 37).

Com base no exposto, podemos dizer que a criança, de até cinco anos ${ }^{3}$, com acesso à educação infantil formal, tem sido furtada do direito de viver a infância e tem sofrido o que Tiriba (2010) denomina "emparedamento da infância". Em sua análise, a autora denuncia que o direito conquistado por meio da Constituição Brasileira de 1988, art. 208, inciso IV5, o qual afirma que será efetivado mediante a garantia do Estado à "[...] educação infantil, em creche e pré-escola, às crianças até 5 (cinco) anos de idade” (BRASIL,

\footnotetext{
3 Pela Lei no 9.394/1996, em seu art. 29 (Redação dada pela Lei $n^{\circ} 12.796$, de 2013), está definido: "A educação infantil, primeira etapa da educação básica, tem por finalidade o desenvolvimento integral da criança de até 5 (cinco) anos, em seus aspectos físico, psicológico, intelectual e social, complementando a ação da família e da comunidade".

4 "Criei a expressão 'emparedar' para designar a ação de manter as crianças entre paredes nos muitos espaços além das salas de atividades das Instituições de Educação Infantil (IEIs) [...] e também para expressar a condição de emparedamento a que são submetidas" (TIRIBA, 2018, p. 17).

${ }^{5}$ Redação dada pela Emenda Constitucional no 53, de 2006.
}

Interfaces da Educ., Paranaíba, v.11, n.32, p. 384 - 411, 2020 
1988) é relativo, uma vez que essas crianças, a partir dos dois anos, permanecem nas instituições de educação infantil de uma a duas horas por dia ao ar livre e em muitos casos em ambientes artificializados com grama sintética, piso acimentado e brita. Sobre esse contexto, a autora adverte que: "[...] se as janelas da sala onde permanecem o restante do tempo não permitem a visão do mundo exterior; se assim os dias se sucedem, essas crianças não conhecem a liberdade... o que foi conquistado como direito, em realidade constitui prisão" (TIRIBA, 2010, p. 6).

Esses argumentos mostram a urgência de se pensar a educação infantil para além das paredes das salas de referência, para além dos muros das instituições e, por sua vez, denunciam a necessidade do desemparedamento das crianças. Ou seja, constatamos na sociedade atual que a responsabilização por criar condições para as crianças explorarem o mundo cabe aos adultos, aspecto que na educação formal, especificamente, cabe aos/às professores/professoras, pois a eles/elas cumpre a tarefa de colocarem em prática as regulações definidas pelas políticas educacionais, voltadas à efetivação de condições para que as crianças exerçam seu direito "de aprendizagem e desenvolvimento", de acordo com a BNCC (BRASIL, 2017b, p. 38), isto é, "conviver, brincar, participar, explorar, expressar e conhecer-se".

Sobre o trabalho a ser realizado na educação infantil, Oliveira (2010, p. 16) esclarece que as práticas pedagógicas nesse nível de escolarização exigem, portanto, que os/as professores/professoras se envolvam “[...] em um amplo processo de renovação de práticas, de revolução de representações cristalizadas sobre a criança, e expectativas acerca do que ela pode aprender". Com relação à "intencionalidade educativa" na educação infantil, a BNCC (BRASIL, 2017b, p. 39) estabelece que "[...] parte do trabalho do educador é refletir, selecionar, organizar, planejar, mediar e monitorar o conjunto das práticas e interações, garantindo a pluralidade de situações que promovam o desenvolvimento pleno das crianças".

Ao refletirmos sobre a pluralidade de situações de aprendizagem que podem ser vivenciadas pela criança, remetemo-nos para além dos espaços Interfaces da Educ., Paranaíba, v.11, n.32, p. 384 - 411, 2020 
formais, pois, como destaca Carbonell (2016), os espaços não formais são mais influentes que a educação escolar no processo de socialização, uma vez que estes poderiam ser um importante ponto de partida para as exigências apresentadas desde 2009 pelo Parecer CNE/CEB n 20 (BRASIL, 2009a, p. 6) sobre práticas "[...] intencionalmente planejadas e permanentemente avaliadas" e que pela BNCC (BRASIL, 2017b, p. 38) "essa intencionalidade consiste na organização e proposição, pelo educador, de experiências que permitam às crianças conhecer a si e ao outro e de conhecer e compreender as relações com a natureza, com a cultura e com a produção científica [...]" (p. 39).

São questões como essas que nos suscitam a pensar a aprendizagem para além dos muros das instituições de educação infantil e para a necessidade de articular espaços, tempos, materiais e oportunidades para que as crianças que frequentam essas instituições educativas vivam a/na cidade como território pedagógico. Lefebvre (2001, p. 117-118) leva-nos a refletir sobre o que denomina "pseudodireito, ou direito à cidade", porquanto "[...] O direito à cidade não pode ser concebido como um simples direito de visita ou de retorno às cidades tradicionais. Só pode ser formulado como direito à vida urbana, transformada, renovada". Essas abordagens alertamnos sobre a necessidade de professores/professoras da educação infantil, no espaço/tempo de formação, compreenderem a cidade como um laboratório de aprendizagens, como estabelecido pelas Diretrizes Curriculares Nacionais para a Educação Infantil (DCNEI) de 2009 ao definir que mais do que garantir o direito da criança de frequentar uma instituição de educação infantil, é fundamental considerar o direito de ela viver a infância e se desenvolver a partir de inúmeras experiências (BRASIL, 2009b).

Tal perspectiva de possibilidades e experiências encaminha-nos para refletir sobre as experiências vividas pelas crianças nos territórios pedagógicos, pois, de acordo com Alves e Brandenburg (2018, p. 24), “[...] ao fazer uso do espaço da cidade para educar e promover o processo de ensinoaprendizagem, realiza-se um processo contínuo de construção e de transformação social", que pode e precisa ocorrer desde a educação infantil. 
Tomar o território da escola, do bairro, do entorno, a cidade como um todo consideramos como um grande laboratório de aprendizagens para os cidadãos que formam a teia de uma sociedade. Sob essa perspectiva, destacamos no conceito de cidade educadora sua ambivalência, que, segundo Zainko (1997, p. 105), "[...] refere-se também e, primordialmente, a realidades e utopias. A utopia de uma sociedade menos desigual, mais humana, mais justa, mais livre e solidária”. Complementando, Alves e Brandenburg (2018, p. 24) indicam que a criança, ao experenciar esse espaço, "[...] apropria-se principalmente de seu caráter social e político, envolvendo a questão da cidadania e da educação".

A concepção de Cidade Educadora teve sua definição estabelecida em 1990, a partir da Declaração de Barcelona, em documento denominado "Carta das Cidades Educadoras", o qual foi revisto no III Congresso Internacional (Bolonha, 1994) e no de Génova (2004), a fim de adaptar as suas abordagens aos novos desafios e necessidades sociais. Com base nesses documentos, cidade educadora é uma instância com personalidade própria, que se relaciona com seu meio e com outros territórios nacionais e internacionais, com o objetivo de aprender, trocar, partilhar e, por consequência, enriquecer a vida dos seus habitantes, erigindo por alvo principal as crianças e os jovens, sem se esquecer de pessoas de todas as idades, numa perspectiva de formação ao longo da vida (AICE 6 , 2004). Sob essa perspectiva, a educação passa a não se limitar a espaços confinados pelos muros da escola e das instituições educacionais, entre as quatro paredes das salas de aula e de referência, mas que essa formação aconteça na vida cotidiana, escrita em um grande livro, como orienta Carbonell (2002, p. 103), ou seja, "[...] um livro aberto que é preciso aprender a olhar e a interpretar e que é um excelente laboratório para trabalhar o processo de

\footnotetext{
6 "Associação Internacional das Cidades Educadoras (AICE) é uma Associação sem fins lucrativos, constituída como uma estrutura permanente de colaboração entre governos locais que se comprometem a reger-se pelos principios inscritos na Carta das Cidades Educadoras. Qualquer governo local que aceite este compromisso pode converter-se em membro ativo da Associação, independentemente das suas competências administrativas". Disponivel em: http://www.edcities.org/pt/quem-somos/. Acesso em: 15 jan. 2020.
} 
trânsito da anedota à categoria, do concreto ao abstrato, das noções isoladas à sua sistematização, da informação ao conhecimento".

Por conseguinte, pensar em como viver a infância para além dos muros das instituições de educação infantil, em interação com seus pares, professoras, comunidade, bairro, cidade, com o mundo natural e social, é um direito das crianças e um compromisso político "[...] que conduz o governo local a direção de incorporar a educação como um eixo estratégico e transversal de seu projeto político" (ALVES; BRANDENBURG, 2018, p. 26). Constatamos, nessa pesquisa, uma das políticas de governo municipal da cidade de Curitiba/PR, intitulada: "Linhas do Conhecimento", a qual "[...] tem como objetivo fortalecer a consciência urbana, a sustentabilidade, a pertença dos sujeitos aos espaços da cidade e a identidade cidadã, envolvendo professores(as) e estudantes em práticas de exploração e conhecimento de Curitiba" (CURITIBA, 2018, p. 11-12). Por meio desse programa, crianças da educação infantil e alunos do ensino fundamental participam de

[...] propostas lúdicas, aulas de campo e/ou propostas culturais e esportivas na cidade, considerando as especificidades do nível ou da modalidade de ensino em que são desenvolvidas. [...] As aulas de campo locais podem ser realizadas a pé no entorno das escolas, regionais e bairros e, por meio da interação, adultos, crianças e jovens exploram espaços próximos às unidades escolares. Essas propostas se caracterizam por valorizar os bairros, as culturas e as comunidades locais, bem como os espaços culturais e esportivos próximos à realidade dos envolvidos" (p. 12).

Essa iniciativa política nos remete a Lefebvre (2001), que descreve a cidade como um lugar de encontro, de necessidades opostas e complementares e de formação, pois "O ser humano tem também a necessidade de acumular energias e a necessidade de gastá-las, e mesmo de desperdiçá-las no jogo. Tem necessidade de ver, de ouvir, de tocar, de degustar, e a necessidade de reunir essas percepções num 'mundo"' (p. 105). E, também, dialoga com Gadotti (2006, p. 138), ao sinalizar que a escola na sociedade da informação é “[...] presente na cidade [... por criar] novos conhecimentos, sem abrir mão do conhecimento historicamente produzido pela humanidade, uma escola científica e transformadora", bem como com Interfaces da Educ., Paranaíba, v.11, n.32, p. 384 - 411, 2020 
Paulo Freire sobre "Educação na Cidade" (1991, p. 24), que ao defender uma prática educativa não neutra, com posicionamento sem uma pretensa imparcialidade, indica que o processo de “[...] reformulação do currículo é sempre um processo político-pedagógico e, para nós, substantivamente democrático".

\section{Teoria das Representações Sociais para compreensão dos fenômenos educacionais}

A Teoria das Representações Sociais (TRS), situada no campo da Psicologia Social, foi concebida na década de 1960 por Serge Moscovici, amplamente divulgada em sua obra La Psychanalyse, son image et son publique (1961). Essa teoria não só reabilita o senso comum, mas considera as representações sociais como constitutivas da realidade, tendo sido aprofundada por seus sucessores que desenvolveram novas abordagens em seus estudos. Dentre eles, situa-se, inicialmente, Denise Jodelet, principal colaboradora no aperfeiçoamento da abordagem processual de Moscovici. Posteriormente sugiram outras, como as de: Willem Doise, com a abordagem societal; Jean-Claude Abric, com a abordagem estrutural e a proposição da Teoria do Núcleo Central (TNC), utilizada nesse estudo para investigar as representações sociais das professoras participantes; e, mais recentemente, Ivana Marková, com a abordagem dialógica.

A base epistemológica da TRS tem oferecido grandes contribuições a diferentes áreas do conhecimento para a compreensão de fenômenos, especialmente, área da saúde e educação. Como ressaltam Wachelke e Camargo (2007, p. 380), o contributo da TRS consiste em "[...] interpretar e conceber aspectos da realidade para agir em relação a eles". O interesse de pesquisadores da educação na investigação das representações sociais justifica-se devido ao “[...] seu papel na orientação de condutas e das práticas sociais, as representações sociais constituem elementos essenciais à análise dos mecanismos que interferem na eficácia do processo educativo" (ALVES-MAZZOTTI, 2008, p. 20-21). Segundo a autora, trata-se de um 
modelo capaz de dar conta dos mecanismos sociais e psicológicos que atuam na produção das representações.

No intuito de pontuar o conceito de representação social, recorremos ao próprio Moscovici (1978, p. 26), quando afirma que "[...] a representação social é uma modalidade de conhecimento particular que tem por função a elaboração de comportamentos e a comunicação entre indivíduos". Jodelet (2001, p. 22), no bojo dessa definição, afirma que a RS pode ser entendida como "[...] uma forma de conhecimento, socialmente elaborada e partilhada, com um objetivo prático, e que contribui para a construção de uma realidade comum a um conjunto social". Moscovici $(1978$, p. 27) ainda esclarece que "[...] uma representação é sempre uma representação de alguém, tanto quanto de alguma coisa". Ou seja, uma representação social envolve sempre um sujeito/grupo e um objeto, que nesta pesquisa são os professores de um grupo selecionado e um objeto por eles representado: "cidade educadora".

Para conhecer o conteúdo e a estrutura dessas representações, optamos pela abordagem estrutural, desenvolvida pelo psicólogo francês Jean-Claude Abric, em 1976, na Université de Provence, que as define como “[...] constituídas de um conjunto de informações, de crenças, de opiniões e de atitudes a propósito de um dado objeto social. Este conjunto de elementos se organizado, estrutura-se e se constitui num sistema sociocognitivo de tipo específico" (ABRIC, 2000, p. 30). Essa abordagem propõe como princípio o de que "[...] toda representação se organiza em torno de um núcleo central. Este núcleo central é o elemento fundamental da representação, pois é ele que determina ao mesmo tempo sua significação e sua organização interna" (ABRIC, 2001, p. 162). De acordo com o autor, as representações sociais incorporam caraterísticas dos sujeitos e dos objetos, constituindo-se em uma estrutura significante, determinada por influências do contexto, e não simplesmente um reflexo da realidade. Portanto, as RS são "[...] o produto e o processo de uma atividade mental pela qual um individuo ou grupo reconstitui a realidade que enfrenta e lhe atribui uma significação específica" $(2001$, p. 31). É nessa persepctiva que a técnica de 
associação livre de palavras foi utilizada nessa pesquisa e também é nela que encontra guarida.

Assim, reforçamos a opção pela abordagem estrutural nessa pesquisa face à necessidade de conhecer o conteúdo, a organização interna e o provável núcleo central (NC) das RS do grupo de professoras participantes desta pesquisa sobre cidade educadora. A dinâmica derivada da organização dos conteúdos de uma RS ocorre pela ação de dois sistemas: o central (SC) e o periférico (SP). O NC que é determinado tanto pela natureza do objeto representado, quanto pelo tipo de relações que o sujeito e o grupo mantêm com esse objeto, além do "[...] sistema de valores e normas sociais que constituem o meio ambiente ideológico do momento e do grupo" (ABRIC, 2000, p. 31).

\section{Percurso metodológico e perfil dos participantes da pesquisa}

Essa pesquisa de abordagem qualitativa e empírica compreendeu a participação de 37 professoras que atuam na etapa da educação infantil na rede municipal de ensino da cidade de Curitiba/PR, engajados no "Programa Linhas do Conhecimento", ofertado pela rede de ensino Municipal de Curitiba/PR, ou seja, professoras que inserem em seus planejamentos propostas do roteiro disponibilizado por esse programa, uma política de governo em vigor desde 2017.

Inicialmente, fizemos contato com a gerência do Programa Linhas do Conhecimento para apresentar a proposta de pesquisa, a fim de descrever possiveis riscos e beneficios, a qual sugeriu o protocolo do projeto para apreciação da superintendência de gestão educacional e demais setores envolvidos. Após autorização escrita para a realização da pesquisa, fornecida pela Secretaria Municipal de Educação (SME), fizemos contato com os gestores dos CMEIs localizados nos Núcleos Regionais (NRE): Bairro Novo, Boqueirão e Pinheirinho, e respectivas professoras concursadas, excluindo as substitutas e as que atuavam há menos de dois anos na rede, para apresentação e esclarecimentos sobre o teor da pesquisa, seus objetivos e a relevância para a rede municipal e o campo da educação. A partir do aceite e Interfaces da Educ., Paranaiba, v.11, n.32, p. 384 - 411, 2020 
da adesão voluntária das professoras por meio da assinatura do Termo de Consentimento Livre e Esclarecido (TCLE), primeiramente, exemplificamos o uso da técnica de associação livre de palavras, utilizando um termo indutor diferente do utilizado na pesquisa e iniciamos a coleta de dados propriamente dita, com a distribuição de protocolos individuais com a expressão indutora: "cidade educadora". Foi solicitado às professoras que, a partir do termo indutor "cidade educadora", escrevessem cinco palavras relacionadas que lhes viessem de imediato à mente e, em seguida, classificassem-nas, por ordem de importância, e justificassem a escolha da palavra mais importante.

A análise das evocações, pela técnica de associação livre de palavras, de acordo com Nascimento-Sehub e Camargo (2000, p. 296), consiste "[...] em uma análise lexicográfica, na qual o índice empírico: 'palavra' corresponde ao 'indicador' elemento de uma representação social". As 178 respostas ao termo indutor pesquisado foram lematizadas e processadas no software EVOC (2000), que gerou um quadro de quatro casas - análise prototípica, o qual, pela análise lexográfica, identifica e classifica os elementos centrais e periféricos da RS e fornece hipóteses quanto aos que são centrais em uma representação.

Posteriormente, com objetivo de confirmar a centralidade dos elementos das RS e conhecer o grau de conectividade entre elas, fizemos uso da análise de similitude (FLAMENT, 1981; ROUSSIAU, 2002) como procedimento adicional para obter resultados mais conclusivos na confirmação da hipótese de centralidade dos elementos situados no $1^{\circ}$ quadrante na análise prototípica. Para tanto, os dados produzidos pela técnica de evocações de palavras foram processados pelo software Iramuteq ${ }^{7}$ (RATINAUD, 2009). Esse programa realiza o cálculo da coocorrência dos vocábulos presentes no quadro de quatro casas, uma vez que se parte do pressuposto de que as palavras evocadas pelas professoras apresentam relação entre si acerca da cidade educadora. O relatório gerado é uma matriz

\footnotetext{
7 Interface de $\mathrm{R}$ pour analyses Multidimensionnelles de Textes et de Questionnaires.
} Software gratuito do tipo open source. Interfaces da Educ., Paranaíba, v.11, n.32, p. 384 - 411, 2020 
gráfica denominada árvore máxima. Esse tipo de procedimento possibilita outro nível de explicitação "[...] tanto do conteúdo quanto da estrutura da representação, confirmando ou questionando a hipótese da centralidade resultante da construção do quadro de quatro casas" (OLIVEIRA et al., 2005, p. 586-587).

Aprofundando a análise dos dados produzidos, apresentamos a árvore máxima sobre cidade educadora, pela qual é possivel observar as áreas ou blocos que ilustram a centralidade dos elementos das RS e a força mais forte de relação entre os vocábulos. Dessa forma, a relevância dessa análise qualitativa depende da interpretação e da compreensão por parte do pesquisador sobre essas relações, o qual não fica restrito aos dados estatísticos provenientes de outros recursos informáticos. Além disso, devido à possivel amplitude de conexões existentes entre os elementos na construção da árvore máxima, definimos como critério de corte $\geq 5$ (maior ou igual a cinco) para a seleção das palavras/vocábulos mais recorrentes, agrupados pelo software em face do grau de conexidade, construindo-se, assim, os principais campos semânticos. O relatório produzido pelo Iramuteq (CAMARGO; JUSTO, 2013) auxiliou na definição do critério, uma vez que esse apresenta a média total da frequência e da conexidade entre todos os vocábulos.

Foram elencados os traços identitários das 37 professoras participantes, como forma de caracterizá-las em relação ao gênero, faixa etária, formação acadêmica e tempo de experiência na educação infantil, sendo 27 do NRE do Bairro Novo e 10 do NRE do Boqueirão, com faixa etária entre 24 a 28 anos (2), 29 a 40 anos (8), de 41 a 50 (20) e acima de 50 anos (7). Em relação à formação acadêmica, seis (6) professoras possuem apenas o Magistério, o que atende ao definido pelo art. 62, da Lei ${ }^{\circ}$ 9.394/1996, que admite docentes com formação em nível médio na modalidade normal, para atuar na educação infantil e nos cinco primeiros anos do ensino fundamental (BRASIL, 1996). A maioria das participantes (15) possui formação em nível superior, Pedagogia, seguido de 11 que cursaram o Magistério e Pedagogia. Quatro professoras indicaram ser licenciadas e Interfaces da Educ., Paranaíba, v.11, n.32, p. 384 - 411, 2020 
apenas uma não respondeu. Em relação ao tempo de experiência como docente na etapa da educação infantil, a maioria delas (30) possui entre 7 a 25 anos, quatro estão entre 4 a 6 anos e dois na faixa de 25 a 35 anos de experiência. Esses dados revelam que a maioria das professoras pesquisadas se identifica com essa etapa de ensino, pois tem mais de sete anos de experiência.

$\mathrm{Na}$ continuidade, apresentamos os resultados e a análise dos dados produzidos.

\section{Representações sociais das professoras de educação infantil na interface com o "Programa Linhas do Conhecimento" sobre cidade educadora}

Complementar à matriz proposta por Moscovici, partimos das orientações de Abric $(2000,2001)$ com a Teoria do Núcleo Central (TNC) para desvelar o conteúdo da RS dos participantes acerca das respostas ao termo indutor "Cidade Educadora", bem como à respectiva organização no sistema central (SC) e periférico (SP), com foco de análise e interpretação do provável NC, sem menosprezar o SP - o qual complementa e dialoga com o NC, que caracteriza a parte rígida da representação mais cristalizada e menos sensivel a mudanças.

A Análise Prototípica das respostas ao termo indutor proposto foi processada pelo EVOC (2005), que gerou um quadro de quatro casas, construído com a Ordem Média de Importância (OMI), conforme sugestão de Wachelke e Wolter (2013). No Quadro 1, os resultados com cada elemento informam a frequência de ocorrência e a ordem média de importância no grupo. A localização desses elementos define "[...] os princípios fundamentais em torno dos quais se constituem as representações" (ABRIC, 2000, p. 33).

Quadro 1: Análise prototípica dos dados obtidos pela Técnica de Associação Livre para o termo indutor "Cidade Educadora", organizados pela OMI 


\begin{tabular}{|c|c|c|c|c|c|}
\hline \multicolumn{3}{|c|}{ Provável Núcleo Central } & \multicolumn{3}{|l|}{$1^{\mathrm{a}}$ Periferia } \\
\hline $\begin{array}{l}\text { Vocábulos/Elemento } \\
\text { s }\end{array}$ & \multicolumn{2}{|c|}{$\begin{array}{l}\text { Freq }>=4 \\
\text { OM }<3\end{array}$} & Vocábulos/Elementos & \multicolumn{2}{|c|}{$\begin{array}{c}\text { Freq }>=4 \\
O M<3\end{array}$} \\
\hline Conhecimento & $\begin{array}{l}1 \\
3 \\
\end{array}$ & $\begin{array}{c}1,69 \\
2\end{array}$ & Aprendizagem & 7 & $\begin{array}{c}3,42 \\
9\end{array}$ \\
\hline Crianças & 5 & $\begin{array}{c}1,60 \\
0\end{array}$ & Cuidado & 5 & $\begin{array}{c}3,20 \\
0\end{array}$ \\
\hline Educação & 6 & $\begin{array}{c}2,83 \\
3\end{array}$ & Parques & 5 & $\begin{array}{c}4,20 \\
0\end{array}$ \\
\hline Escolas & 4 & $\begin{array}{c}3,00 \\
0\end{array}$ & & & \\
\hline Professoras & 5 & $\begin{array}{c}2,40 \\
0\end{array}$ & & & \\
\hline \multicolumn{3}{|c|}{ Zona de Contraste } & \multicolumn{3}{|l|}{$2^{a}$ Periferia } \\
\hline Vocábulos/Elementos & \multicolumn{2}{|c|}{$\begin{array}{l}\text { Freq }<4 \\
\text { OM }<3\end{array}$} & $\begin{array}{l}\text { Vocábulos/Elemento } \\
\text { s }\end{array}$ & \multicolumn{2}{|c|}{$\begin{array}{c}\text { Freq }<4 \\
\text { OM }<3\end{array}$} \\
\hline Capacitação & 2 & $\begin{array}{c}2,00 \\
0 \\
\end{array}$ & Deveres & 2 & $\begin{array}{c}4,50 \\
0\end{array}$ \\
\hline Cidadania & 3 & $\begin{array}{c}2,66 \\
7\end{array}$ & Espaços & 2 & $\begin{array}{c}4,00 \\
0\end{array}$ \\
\hline Comprometimento & 2 & $\begin{array}{c}2,50 \\
0 \\
\end{array}$ & Gestão & 2 & $\begin{array}{c}3,50 \\
0\end{array}$ \\
\hline Conscientização & 2 & $\begin{array}{c}1,50 \\
0 \\
\end{array}$ & Modernidade & 2 & $\begin{array}{c}5,00 \\
0\end{array}$ \\
\hline Cultura & 3 & $\begin{array}{c}3,00 \\
0\end{array}$ & Museus & 2 & $\begin{array}{c}4,00 \\
0\end{array}$ \\
\hline Curitiba & 2 & $\begin{array}{c}2,00 \\
0\end{array}$ & Passeios & 2 & $\begin{array}{c}4,00 \\
0\end{array}$ \\
\hline Direito & 2 & $\begin{array}{c}3,00 \\
0\end{array}$ & Pesquisa & 3 & $\begin{array}{c}4,00 \\
0\end{array}$ \\
\hline Histórias & 3 & $\begin{array}{c}3,00 \\
0\end{array}$ & População & 3 & $\begin{array}{c}4,66 \\
7\end{array}$ \\
\hline Inclusão & 3 & $\begin{array}{c}2,66 \\
7\end{array}$ & Projeto & 2 & $\begin{array}{c}4,00 \\
0\end{array}$ \\
\hline Participativa & 2 & $\begin{array}{l}2,00 \\
0\end{array}$ & & & \\
\hline Pessoas & 3 & $\begin{array}{c}2,00 \\
0 \\
\end{array}$ & & & \\
\hline Profissionais & 2 & $\begin{array}{c}3,00 \\
0\end{array}$ & & & \\
\hline Propostas & 2 & $\begin{array}{c}2,50 \\
0\end{array}$ & & & \\
\hline Respeito & 3 & $\begin{array}{c}2,00 \\
0\end{array}$ & & & \\
\hline Sabedoria & 3 & $\begin{array}{c}2,66 \\
7\end{array}$ & & & \\
\hline Valorização & 2 & 2,50 & & & \\
\hline
\end{tabular}

Interfaces da Educ., Paranaíba, v.11, n.32, p. 384 - 411, 2020 
Fonte: as autoras, com base nos dados da pesquisa gerados pelo EVOC (2005), em 2020.

Em face do critério de corte adotado, os elementos (palavras/vocábulos) que integraram o provável NC foram: "conhecimento" $($ Freq $=13, \mathrm{OM}=1,693)$, “educação" (Freq = 6, OM = 2,833), "crianças" (Freq $=5, \mathrm{OM}=1,600)$ "professoras" (Freq $=5, \mathrm{OM}=2,200)$ " e "escolas" (Freq $=4$, $\mathrm{OM}=3,000)$.

A análise do quadro 1 permitiu visualizar a distribuição dos elementos que configuram a RS de professoras que atuam nas turmas de pré-escola na educação infantil sobre "cidade educadora" e, em construção, justamente, por admitirmos que a constituição de RS é contínua, isto é, "[...] não mais uma vida social já feita, mas uma vida em vias de se fazer" (MOSCOVICI, 2003, p. 65). Ressaltamos que, segundo Abric (2000), o núcleo central abarca elementos mais estáveis da RS, mais cristalizados, ou seja, mais resistentes à mudança, assegurando a sua continuidade em contextos móveis e evolutivos. Abric (2000, p. 31) complementa que “[...] além disso, o NC possui uma dimensão qualitativa, pois o que define a centralidade de um elemento não é sua presença maciça, mas, sim, o seu significado à representação".

Sobre os resultados da OMI (Quadro 1) no provável núcleo central, destacamos a palavra "conhecimento", a qual desponta com alta frequência e a mais prontamente evocada por 13 professoras, podendo ser considerada o cerne da representação para o grupo pesquisado, o qual, na escolha dela como a mais importante, apresentou, por exemplo, as seguintes justificativas: "O conhecimento do espaço ou do lugar que propomos conhecer" (P34); “Conhecer, se apropriar de diversas oportunidades que lhe são oferecidas para agregar em seu conhecimento, para poder compartilhar com o outro (P28); "É importante termos conhecimento para serem bem informados" (P05). Ainda, para a P31, "Conhecimento: onde vivemos; cultura; cuidar de onde vivemos; aprender sobre os antepassados; dividir com a comunidade o que aprendemos". A palavra "conhecimento", nas 
representações sociais sobre "Cidade Educadora" dessas professoras de educação infantil, ainda remete-nos ao sentido amplo da palavra, enquanto direito ao desenvolvimento integral da criança em todas as suas dimensões, garantido pela Constituição Federal de 1988 e pela LDB (1996), além de nos evocar a necessária construção e reelaboração do conhecimento por parte dos/das professores/professoras e, simultaneamente, que ele assuma, junto às crianças com as quais trabalha, "[...] responsabilidade ética, política e profissional do ensinante lhe coloca o dever de se preparar, de se capacitar [...]" (FREIRE, 1996, p. 19). Em discussão sobre o conhecimento na era da informação, Carbonell (2002) destacou o quanto a informação e o conhecimento se renovam de forma acelerada, em face dos avanços tecnológicos, redes sociais, internet das coisas, entre outras questões que marcam o século XXI, defendendo que se faz necessário que todos desenvolvam a capacidade de codificar as informações, contextualizá-las, organizá-las, interpretá-las, de forma a darem sentido e as transformarem em conhecimento, desafio este que a escola precisa enfrentar, exigindo de todos que atuam nessas instituições a inovação pedagógica. A palavra "educação" alerta para o objetivo da cidade educadora voltado ao aprender, trocar, partilhar e a preocupação prioritária com a educação de crianças e jovens, sem deixar de pensar na educação ao longo da vida (AICE, 2004), aspecto que vem ao encontro da justificativa da P02: "Acredito que a educação é a base para tudo, desde o conhecimento adquirido na escola até a vida que se segue depois dos anos acadêmicos".

$\mathrm{Na}$ primeira periferia, a palavra "aprendizagem" destaca-se por sua alta frequência, associada a "cuidado" e "parques", que complementam o provável $\mathrm{NC}$, ao que podemos inferir o saber das professoras aqui representadas de que a escola não é o único espaço de construção de conhecimento e que para além dos muros das instituições de educação infantil e das escolas de ensino fundamental e médio, existem inúmeros territórios pedagógicos, já que a educação se dá ao longo da vida e, como orienta Moscovici (2003), as RS nos preparam para a ação. A Zona de Contraste revela que as RSs estão em processo de transformação, podendo Interfaces da Educ., Paranaíba, v.11, n.32, p. 384 - 411, 2020 
seus conteúdos constituir, futuramente, o núcleo central para o grupo pesquisado. Sobre a interlocução dos/das professores/professoras com a cidade educadora, Carbonell (2002) orienta que estes não são os únicos agentes informativos ou formativos, mas que lhes compete a função de coordenar e orientar o conjunto de contribuições culturais apreendidas dos diversos agentes e cenários do seu território.

Ao aprofundarmos a análise das RS, utilizamos a Análise de Similitude (Figura 1) expressa na árvore máxima elaborada com base nos dados obtidos pela Análise Prototípica (Quadro 1), a qual nos permitiu visualizar a conexidade entre as palavras e depreender a centralidade dos elementos das RS para o grupo de professoras participantes, aqui revelada pelos blocos "conhecimento", "educação", seguido de "crianças", "professoras" e "escola".

O bloco "conhecimento" ganha destaque devido à sua maior coocorrência entre as palavras, confirmando a hipótese da centralidade dos elementos da RS obtida na análise prototípica. Conhecimento está associado, principalmente, a "cuidado" e "aprendizagem". Considerando que as participantes da pesquisa são professoras que atuam nas turmas de préescola da educação infantil, suas representações revelam o disposto nas Diretrizes Curriculares Nacionais para a Educação Infantil (2009), nas Diretrizes Curriculares Nacionais Gerais para a Educação Básica (2010), reafirmado na BNCC (BRASIL, 2017b), quando se evidencia o educar e o cuidar como indissociáveis, porquanto, "Educar exige cuidado; cuidar é educar, envolvendo acolher, ouvir, encorajar, apoiar, no sentido de desenvolver o aprendizado de pensar e agir, cuidar de si, do outro, da escola, da natureza, da água, do planeta” (BRASIL, 2010). Ou seja, a conexidade entre a construção do conhecimento permeado pelo cuidar e educar, concepção cristalizada face às especificidades do público em destaque, crianças de 4 a 5 anos idade, que frequentam a educação infantil e as possibilidades de aprendizagem em diferentes ambientes, alguns já evidenciados na árvore máxima (Figura 1) elaborada a partir das evocações em suas extremidades, intimamente ligadas com o programa "Linhas do 
Conhecimento", propostas que envolvem a ampliação cultural, com visitas a parques, museus, passeios etc.

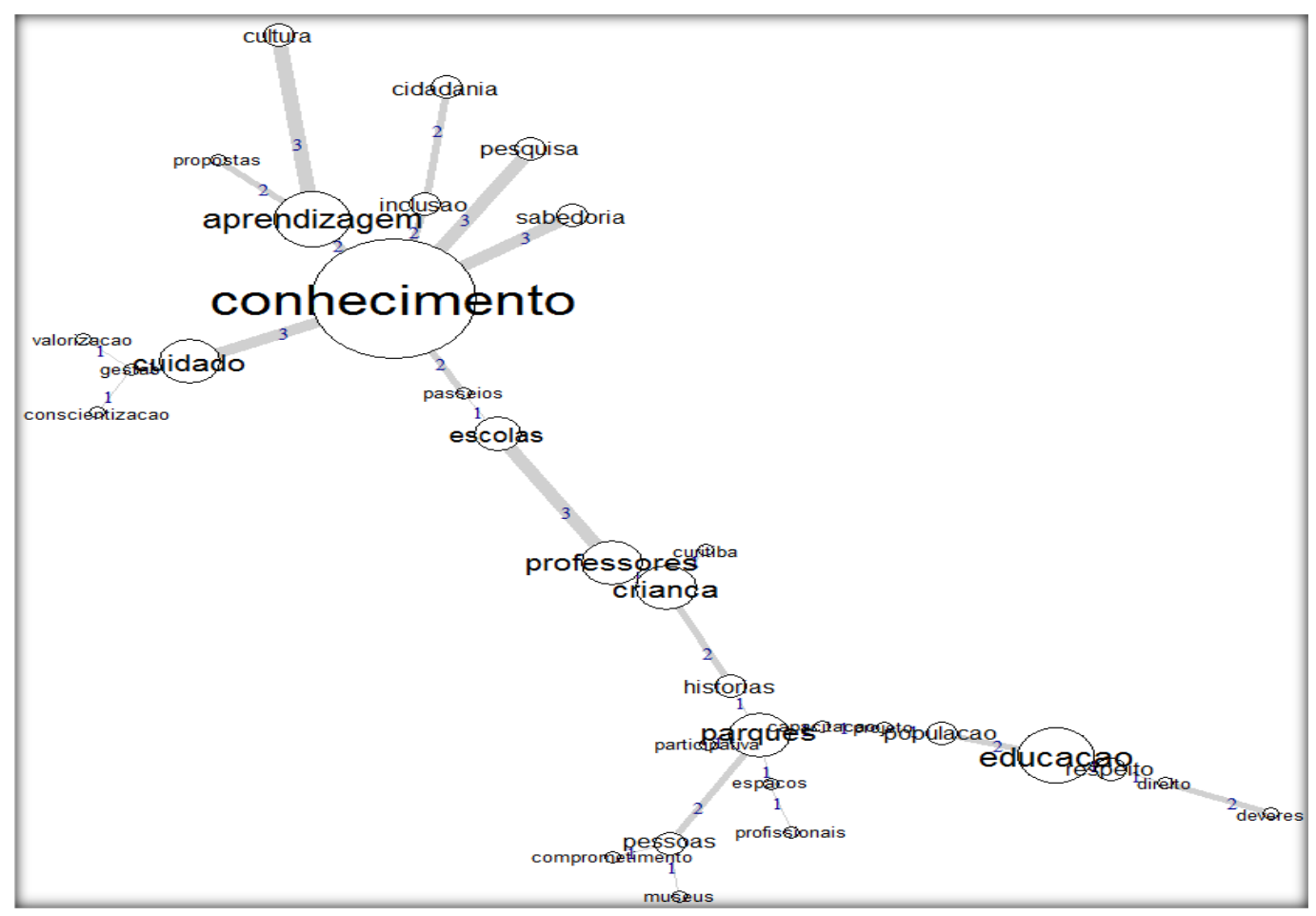

Figura 1 - Árvore Máxima de Similitude da RS “Cidade Educadora” Fonte: as autoras, 2020.

Ressaltamos que o programa acarreta um novo paradigma de trabalho pelo qual as aulas-passeio dão lugar às aulas de campo e propostas lúdicas, porém, independentemente ao momento transicional de compreensão e de novas concepções, a evocação de tais espaços pelas professoras participantes revela o reconhecimento da ampliação de territórios pedagógicos possiveis às crianças e às professoras para além dos muros das instituições. Outro dado apontado na árvore máxima é a presença da palavra inclusão, evidenciada nos principios de uma cidade, no que tange ao compromisso da cidade educadora no que preconiza que o espaço físico urbano deverá estar de acordo com as “[...] necessidades de acessibilidade, encontro, relação, jogo e lazer e de uma maior aproximação à natureza. A cidade educadora deverá conceder um cuidado especial às necessidades das pessoas com dependência no planejamento urbanístico de equipamentos e serviços" (AICE, 2004, p. 6). 
Essas professoras revelam perceber que para além do espaço escolar, como defende Bernet (1997), é possivel que todos aprendam na cidade (cidade como espaço no qual a aprendizagem ocorre), aprendam com a cidade (cidade lida como texto, como emissora constante de aprendizados) e aprendam a cidade (cidade como intervenção, passível de transformação, de ação política). Contudo, faz-se necessário o respeito às diferenças e a adequação dos espaços públicos, de modo que ofereçam acessibilidade a todos, de acordo com suas necessidades.

Outro bloco da Figura 1 abarca a palavra "educação", a qual, de acordo com as Diretrizes Curriculares Nacionais para a Educação Básica (2010), é "[...] processo e prática que se concretizam nas relações sociais que transcendem o espaço e o tempo escolares, tendo em vista os diferentes sujeitos que a demandam". Sublinhando com vigor: "Educação consiste, portanto, no processo de socialização da cultura da vida, no qual se constroem, se mantêm e se transformam saberes, conhecimentos e valores" (BRASIL, 2010). Em se tratando da educação que transcenda o espaço e tempo escolares, Carbonell (2016, p. 18) ressalta: “[...] cidade educativa ou educadora é uma das mais belas utopias que se propõe a converter a cidade em uma enorme fonte de estímulos e recursos educativos, que estão a serviço da formação integral de todos os cidadãos".

A análise prototípica das representações sociais das professoras de educação infantil sobre Cidade Educadora (Quadro 1) revela que estão cientes da importância de uma educação em interlocução com seu entorno físico e cultural e por meio da árvore máxima (Figura 1) demonstra-se uma mobilidade e transformação de saberes e conhecimentos, os quais podem ser atribuídos, neste momento, ao convite, aceite e desafio que o programa Linhas do Conhecimento faz às professoras, qual seja, o de transcenderem as paredes das salas de referência e muros das instituições para que as crianças, junto de suas professoras, possam viver a/na cidade, mesmo que de forma gradativa e tímida ainda, mas com prognóstico de inúmeras possibilidades de aprendizagem. 


\section{Algumas considerações}

A análise das representações sociais apresentadas pelas professoras participantes, de cidade educadora, fundamentada na teoria de Moscovici, em sua vertente complementar (TNC de Abric), demarca a compreensão inicial dessas 37 professoras de educação infantil acerca do potencial da cidade como território pedagógico, bem como seu papel no contexto da educação infantil para assegurar uma formação para/pela cidadania ativa. Inferimos isso a partir dos dois tipos de análise realizados da RS sobre cidade educadora, principalmente, com a presença de "conhecimento" prontamente evocado e alto valor simbólico.

Por outro lado, por considerarmos que as representações sociais "[...] são, ao mesmo tempo, construídas e adquiridas" (MOSCOVICI, 2003, p. 62), inferimos a partir da zona de contraste (Quadro 1), pelas palavras evocadas por um pequeno número de participantes, porém de alto valor simbólico, a possibilidade da presença de um movimento de re(construção) das representações sociais de cidade educadora para esse grupo de professoras participantes, ou seja, tomar a cidade como comunidade educadora e sua contribuição para assegurar à criança os direitos de cidadania. Essas constatações levam-nos a depreender que estas, ao apoiarem-se no currículo local e nas propostas pedagógicas das instituições de educação infantil, estabelecem em seu planejamento como fundamental que as crianças vivam o bairro e a cidade como territórios pedagógicos, a fim de promover a pertença dos indivíduos com seu entorno e locais mais distantes da cidade, ao interagirem com seus pares, com os recursos pedagógicos e, principalmente, com o seu meio.

Dessa compreensão, partimos do pressuposto de que para promover o direito à cidade, segundo Lefebvre (2001), cabe ao professor na educação infantil instigar o rompimento de práticas estereotipadas, centradas na visão adultocêntrica, processo que exige do professor autorreflexão constante de suas práticas. Além disso, como aponta Nóvoa (2009), é preciso que se some a essa reflexão sobre as práticas a participação em programas de formação continuada e que estes sejam lugar e tempo oportunos para a troca entre os Interfaces da Educ., Paranaíba, v.11, n.32, p. 384 - 411, 2020 
pares e parceiros mais experientes, de modo a superar práticas que contenham o "emparedar de crianças", como alerta Tiriba $(2010,2018)$. São as RS sobre cidade educadora dessas professoras que nos mostram que uma cidade, ao ser tomada em seu espaço/tempo, poderá envolver a ampliação cultural, criar uma comunidade educadora e contribui para assegurar à criança os direitos de cidadania e requerer a valorização do professor.

\section{Referências}

ABRIC, J.-C. A abordagem estrutural das representações sociais. In: MOREIRA, A. S. P.; OLIVEIRA, D. C. de (Org.). Estudos interdisciplinares de representação social. Goiânia: AB, 2000. p. 27-38.

ABRIC, J.-C. Las representaciones sociales: aspectos teóricos. In: ABRIC, J.C. (Org.). Prácticas sociales y representaciones. Tradução José Dacosta Chevrel y Fátima Flores Palacios. México: Ediciones Coyoacán; Ambassade de France-CCC IFAL, 2001. p. 11-32.

AICE. Associação Internacional das Cidades educadoras. Carta das Cidades Educadoras, 2004. Disponivel em: http://www.edcities.org/pt/carta-dascidades-educadoras/. Acesso em: 27 set. 2019.

ALVES, A. R.; BRANDENBURG, E. J. Cidades educadoras: um olhar acerca da cidade que educa. Curitiba: InterSaberes, 2018.

ALVES-MAZZOTTI, A. J. Representações sociais: aspectos teóricos e aplicações à educação. Revista Múltiplas Leituras, Brasília, DF, v. 1, p. 1843, jan./jun. 2008.

ARRUDA, A. Representações sociais: dinâmicas e redes. In: SOUSA, C. P. et al. (org.). Angela Arruda e as Representações Sociais: estudos selecionados. Curitiba: Champagnat; São Paulo: Fundação Carlos Chagas, 2014. p. 117146.

BELLOT, P. F. Cidades educadoras, uma aposta de futuro. In: AICE Associação Internacional das Cidades Educadoras. Educação e vida urbana: 20 anos de Cidades Educadoras. Lisboa: Gráfica Almondina (Torres Novas, Portugal), 2013. p. 17-22. Disponível em: http://www.edcities.org/wp- 
content/uploads/2015/11/livro-20-anos-cidades-educadoras-PT.pdf.

Acesso em: 16 mar. 2020.

BERNET, J. T. Ciudades educadoras: bases conceituais. In: ZAINKO, M. A. S.; SCHWARTZ, A. et al. Cidades Educadoras. Curitiba: Ed. da UFPR, 1997. p. 13-34.

BRASIL. Constituição da República Federativa do Brasil. Brasília, DF: Senado Federal, 1988.

BRASIL. Ministério da Educação. Base Nacional Comum Curricular (BNCC). Educação é a Base. Brasília, DF: MEC/CONSED/UNDIME, 2017b.

Disponivel em: http://basenacionalcomum.mec.gov.br/. Acesso em: 21 mar. 2020.

BRASIL. Ministério da Educação. Conselho Nacional da Educação. Câmara de Educação Básica. Parecer n ${ }^{\circ}$ 20, de 11 de novembro de 2009. Revisão das Diretrizes Curriculares Nacionais para a Educação Infantil. Diário Oficial da União, Brasília, DF, 9 dez. 2009a. Disponível em:

http://portal.mec.gov.br/dmdocuments/pceb020_09.pdf. Acesso em: 06 jun. 2019.

BRASIL. Ministério da Educação. Conselho Nacional da Educação. Câmara de Educação Básica. Resolução CNE/CEB, nº 5, de 17 de dezembro de 2009. Fixa as Diretrizes Curriculares Nacionais para a Educação Infantil. Diário Oficial da União, Brasília, DF, 18 dez. 2009b. Disponivel em: http: / / portal.mec.gov.br/programa-curriculo-em-movimento-sp1312968422/legislacao. Acesso em: 01 jun. 2019.

BRASIL. Ministério da Educação. Conselho Nacional de Educação. Câmara de Educação Básica. Resolução CNE/CEB n 4, de 13 de julho de 2010. Define Diretrizes Curriculares Nacionais Gerais para a Educação Básica. Diário Oficial da União, Brasília, DF, 13 de jul. 2010b. Disponivel em: http://portal.mec.gov.br/dmdocuments/rceb004_10.pdf. Acesso em: 12 jan. 2020.

BRASIL. Ministério da Educação. Conselho Nacional de Educação. Conselho Pleno. Resolução CNE/CP, n ${ }^{\circ}$ 2, de 22 de dezembro de 2017a. Institui e orienta a implantação da Base Nacional Comum Curricular, a ser respeitada obrigatoriamente ao longo das etapas e respectivas modalidades no âmbito da Educação Básica. Diário Oficial da União, Brasília, DF, 22 dez. 2017, Seção 1, p. 41 a 44. Disponível em: 
http:/ / basenacionalcomum.mec.gov.br/images/historico/RESOLUCAOCNE CP222DEDEZEMBRODE2017.pdf. Acesso em: 13 jan. 2020.

BRASIL. Presidência da República. Lei n. 9.394, de 20 de dezembro de 1996. Estabelece as diretrizes e bases da educação nacional. Diário Oficial da União, Brasilia, DF, 23 dez. 1996. Disponivel em: http://www.planalto.gov.br/ccivil_03/leis/19394.htm. Acesso em: 07 jun. 2019.

CAMARGO, B. V.; JUSTO, A. M. Iramuteq: um software gratuito para análise de dados textuais. Temas de Psicologia, Ribeirão Preto, SP, v. 21, n. 2, p. 513-518, 2013.

CAMARGO, B. V.; WACHELKE, J. F. R.; AGUIAR, A. Desenvolvimento metodológico das pesquisas sobre representações sociais em jornadas internacionais de 1998 a 2005. In: MOREIRA, A. S. P.; Camargo B.V. Contribuições para a teoria e o método de estudos das representações sociais. João Pessoa: Editora Universitária da UFPB, 2007. p. 181-202.

CARBONELL, J. A aventura de inovar: a mudança na escola. Tradução Fátima Murad. Porto Alegre: Artmed, 2002.

CARBONELL, J. Pedagogias do século XXI: bases para a inovação educativa. Porto Alegre: Penso, 2016.

CURITIBA. Prefeitura Municipal de Curitiba. Secretaria Municipal da Educação. Linhas do Conhecimento. 2018. Disponivel em: https://mideducacao.curitiba.pr.gov.br/2019/9/pdf/00242149.pdf. Acesso em: 26 out. 2019.

FLAMENT, C. L'Analyse de Similitude: une technique pour les recherches sur les représentatiosn sociales. Cahiers de Psychologie Cognitive, Marseille, n. 4, p. 357-396, 1981.

FOUCAULT, M. Vigiar e punir. nascimento da prisão. Tradução Raquel. Ramalhete. Petrópolis, RJ: Vozes, 2007.

FREIRE, P. A educação na cidade. São Paulo: Cortez, 1996. 
FREIRE, P. Pedagogia da autonomia: saberes necessários à prática educativa. Ed. Especial. 37. ed. São Paulo: Paz e Terra, 1996. (Coleção Leitura).

GADOTTI, M. A escola na cidade que educa. Cadernos CENPEC, n. 1, 2006.

JODELET, D. As representações sociais: um dominio em expansão. In: JODELET, Denise (org.). As representações sociais. Tradução Lilian Ulup. Rio de Janeiro: EdUERJ, 2001. p. 17-44.

LEFEBVRE, H. O direito à cidade. Tradução Rubens Eduardo Frias. São Paulo: Centauro 2001.

MOLL, J. A cidade e os seus caminhos educativos: escola, rua e itinerários juvenis. In: AICE - Associação Internacional das Cidades Educadoras. Educação e vida urbana: 20 anos de Cidades Educadoras. Lisboa: Gráfica Almondina (Torres Novas, Portugal), 2013. p. 213-224. Disponivel em: http://www.edcities.org/wp-content/uploads/2015/11/livro-20-anoscidades-educadoras-PT.pdf. Acesso em: 16 mar. 2020.

MOSCOVICI, S. A representação social da psicanálise. Tradução Álvaro Cabral. Rio de Janeiro: Zahar Editores, 1978.

MOSCOVICI, S. La psycganalyse: son image et son public. Paris: Presses Universitaires de France - PUF, 1961.

MOSCOVICI, S. Representações Sociais: investigações em psicologia social. Tradução do inglês Pedrinho A. Guareschi. Petrópolis, RJ: Vozes, 2003.

NASCIMENTO-SEHUB, C. M.; CAMARGO, B. Psicologia social: representações sociais e métodos. Temas em Psicologia da SBP, Ribeirão Preto, v. 8, n. 3, p. 287-299, abr. 2000. Disponível em: http://pepsic.bvsalud.org/pdf/tp/v8n3/v8n3a07.pdf. Acesso em: 24 mar. 2020.

NÓVOA, A. Professoras: imagens do futuro presente. Lisboa: Educa, 2009.

OLIVEIRA, D. C. et al. Análise das evocações livres: uma técnica de análise estrutural das representações sociais. In: MOREIRA, A. S. P. et al. (Org.). 
Perspectivas teórico-metodológicas em representações sociais. João Pessoa: UFPB Editora Universitária, 2005. p.573-603.

OLIVEIRA, Z. R. Currículo na educação infantil: o que propõem as novas diretrizes nacionais? In: I SEMINÁRIO NACIONAL: CURRÍCULO EM MOVIMENTO - PERSPECTIVAS ATUAIS. Anais... Belo Horizonte, 2010, p. 14. Disponivel em: http://portal.mec.gov.br/docman/dezembro-2010pdf/7153-2-1-curriculo-educacao-infantil-zilma-moraes/file. Acesso em: 16 mar. 2020.

POZO, J. M. O conceito de cidade educadora, hoje. In: AICE - Associação Internacional das Cidades Educadoras. Educação e vida urbana: 20 anos de Cidades Educadoras. Gráfica Almondina (Torres Novas, Portugal), 2013. p. 23-34. Disponivel em: http://www.edcities.org/wpcontent/uploads/2015/11/livro-20-anos-cidades-educadoras-PT.pdf. Acesso em: 16 mar. 2020.

RATINAUD, P. Iramuteq: interface de $\mathrm{R}$ pour les analyses multidimensionnelles de textes et de questionnaires [Computer software], 2009. Disponivel em: http://www.iramuteq.org. Acesso em: 4 maio 2019.

ROUSSIAU, N. Similitud analysis: a methodology for studying the structure of social representations. European Review of Applied Psychology, França, v. 52, n. 3-4, p. 293-304, 2002.

TIRIBA, L. Crianças da Natureza. In: I SEMINÁRIO NACIONAL: CURRÍCULO EM MOVIMENTO - PERSPECTIVAS ATUAIS. Anais... Belo Horizonte. p. 9. Disponivel em: portal.mec.gov.br/docman/dezembro-2010-\%20pdf/7161-29-artigo-mec-criancas-natureza-lea-tiriba. Acesso em: 26 out. 2019.

TIRIBA, Léa. Educação infantil como direito e alegria: em busca de pedagogias ecológicas, populares e libertárias. Rio de Janeiro: Paz e Terra, 2018.

WACHELKE, J. F. R.; CAMARGO, B. V. Representações sociais, representações individuais e comportamento. Revista Interamericana de Psicologia/Interamerican Journal of Psychology, Porto Alegre, v. 41, n. 3, p. 379-390, 2007.

WACHELKE, J. F. R.; WOLTER, R. Critérios de construção e relato da análise prototípica para representações sociais. Psicologia: Teoria e Pesquisa, Brasília, v. 27, n. 4, p. 521-526, 2011. Disponivel em: http://www.scielo.br/pdf/ptp/v27n4/17.pdf. Acesso em: 15 jan. 2018. ZAINKO, M. A. S. et. al. Cidades Educadoras. Curitiba: Editora da UFPR, 1997. 